\title{
Mechanism of Mouse Germ Cell Specification: A Genetic Program Regulating Epigenetic Reprogramming
}

\author{
M.A. Surani, K. Ancelin, P. Hajkova, U.C. Lange, B. Payer, P. Western, ${ }^{*}$ and M. Saitou ${ }^{\dagger}$ \\ Wellcome Trust Cancer Research UK Gurdon Institute of Cancer and Developmental Biology, University of \\ Cambridge, Cambridge CB2 1QR, United Kingdom
}

Specification of germ cells and their segregation from somatic neighbors is one of the most decisive events of early development in animals. There are two key routes to the initiation of the germ cell lineage. One is through the inheritance of preformed germ cell determinants or germ plasm as observed in Drosophila melanogaster and Caenorhabditis elegans (Eddy 1975; Wylie 1999). The other route, which is sometimes referred to as the stem cell model, occurs in the mouse, where a group of pluripotent cells are first established with seemingly equivalent potential from which both germ cells and somatic cells are derived (McLaren 1999; Saitou et al. 2003). These two modes of germ cell specification are referred to as preformation and epigenesis, respectively (Fig. 1). Although preformation is observed in most model organisms, it is apparently a less dominant mode of germ cell specification, and epigenesis may be ancestral to the Metazoa (Extavour and Akam 2003).

Primordial germ cells (PGCs), the precursors of sperm and eggs, are the source of totipotency, which is a unique state generated by this lineage. Throughout the period of specification of PGCs and the extensive epigenetic reprogramming of the genome, germ cells require robust mechanisms to ensure that they do not undergo differentiation into somatic cells or revert to an overtly pluripotent state. Furthermore, as transmitters of genetic and epigenetic information to all subsequent generations, PGCs exhibit profound epigenetic reprogramming of the genome, which in mammals includes erasure and initiation of parental imprints that are responsible for the functional differences between the parental genomes during mammalian development (Surani 2001). Genetic mechanisms involved in PGC specification produce a lineage with the essential property of extensive epigenetic reprogramming of the genome that ensues after they reach developing gonads (Surani 2001; Hajkova et al. 2002; Lee et al. 2002). Thus, mechanisms that are involved in PGC specification, maintenance, and epigenetic reprogramming are of considerable general interest in the context of studies on embryonic and adult stem cells.

\footnotetext{
"Present address: ARC Center for Development and Biotechnology, Murdoch Children's Hospital, Parkville, Victoria 3052, Australia.

${ }^{\dagger}$ Present address: Laboratory for Mammalian Germ Cell Biology, Center for Developmental Biology, RIKEN Kobe Institute, Chuo-ku, Kobe, Hyogo 650-0047, Japan.
}

Although specification of the germ line is one of the most crucial events of early animal development, the mechanisms involved are surprisingly not evolutionarily conserved. This is apparently necessary because of the vital differences in early development of different species (Saitou et al. 2003; Schaner et al. 2003; Blackwell 2004). Compared to D. melanogaster and C. elegans, for example, specification of germ cells in mammals is considerably delayed (McLaren 1999). This is evident since the first requirement in mammals is development of a blastocyst, and specification of PGCs occurs later after blastocyst implantation. It is the pluripotent epiblast cells of the egg cylinder of the early postimplantation embryo, which is the source of both PGCs and somatic cells, that are specified in response to signaling molecules (Lawson and Hage 1994; Lawson et al. 1999). Incidentally, the early epiblast cells are also the source of pluripotent embryonic stem (ES) cells, which also have the potential to generate both somatic and germ cells in vitro and in vivo (Hubner et al. 2003; Toyooka et al. 2003; Geijsen et al. 2004; Surani 2004). Despite the essential differences in the mechanisms of germ cell specification observed in different organisms, there are nevertheless certain underlying principles, such as the repression of the somatic program in germ cells, which may be conserved among organisms, as are some of the molecules and mechanisms for the maintenance and propagation of the germ cell lineage.

\section{REPRESSION OF SOMATIC PROGRAM: A COMMON THEME DURING PGC SPECIFICATION}

The repression of somatic cell fate is a common feature observed in founder germ cells of all the animals studied in detail (Seydoux and Strome 1999; Saitou et al. 2003; Blackwell 2004). Disruption to germ line silencing is detrimental to the maintenance of the germ cell lineage. At the onset of germ cell specification in D. melanogaster and $C$. elegans, which occur very early during development, global repression of transcription prevents germ cells from acquiring a somatic fate (Leatherman and Jongens 2003). In mammals where PGC specification occurs at a later stage of development, there is targeted and active repression of genes that are specifically expressed in the neighboring somatic mesoderm cells, which share common developmental ancestry (see below). Until re- 


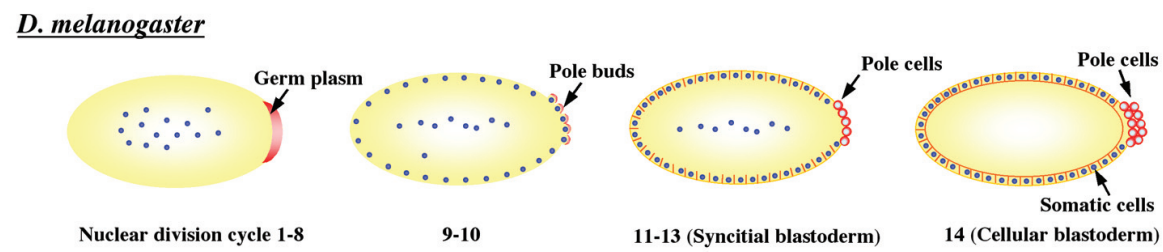

\section{C. elegans}

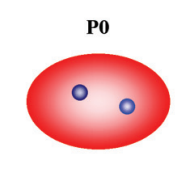

1-cell

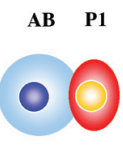

2-cell

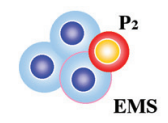

4-cell

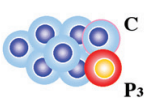

8-cell

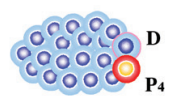

16-24 cell

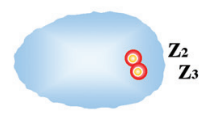

$\sim 100$-cell

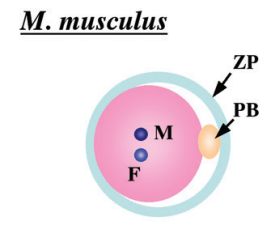

Fertilised oocyte

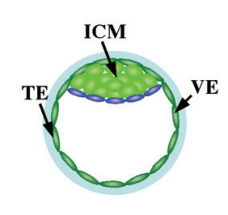

Blastocyst (E3.5-4.0)

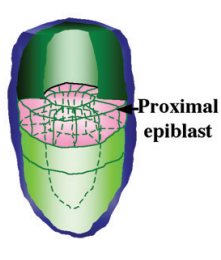

E6.25(PS)

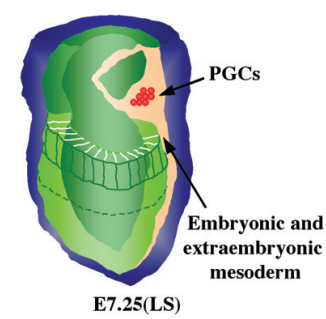

Figure 1. Specification of germ cells in different model organisms. In Drosophila melanogaster, those nuclei that enter the germ plasm induce the formation of pole cells, which give rise to germ cells. In Caenorhabditis elegans, the P0 blastomere divides to form the AB somatic blastomere and P1 germ line blastomere. The latter eventually gives rise to Z2 and Z3 cells, which develop into germ cells. In Mus musculus, germ cells originate from the pluripotent proximal epiblast cells of E6.25 embryos. By E7.25, a group of about 50 founder primordial germ cells (PGCs) are detected.

cently, it was not known that repression of the somatic program is likely to be a critical event during PGC specification in mice. We now have the first indications of a possible mechanism involved in this process, which may be a critical component of PGC specification.

Specification of germ cells in Drosophila represents one extreme, where pole cells, the precursors of germ cells, are set aside from the somatic lineage at the very outset even before the onset of zygotic transcription and cellularization. Specific mechanisms of transcriptional repression are used to escape from a somatic program adopted by the remaining cells. Notably, transcriptional repression in pole cells is achieved by the lack of phosphorylation of RNA polymerase II carboxy-terminal domain (CTD) repeat on serine at position 2 that is essential for transcriptional elongation and by the low levels of CTD phosphorylation on serine at position 5, a modification that is essential for transcription initiation (Seydoux and Dunn 1997; Van Doren et al. 1998; Zhang et al. 2003). Recent studies have shown that the regulation of transcriptional silencing in these putative germ cells requires polar granule component $(\mathrm{pgc})$ gene, a noncoding RNA (Deshpande et al. 2004; Martinho et al. 2004). Absence of $p g c$ results in the loss of repression, but this does not affect the formation of pole cells. The mutant pole cells display a precocious phosphorylation of ser2 of CTD. How precisely $p g c$ works is currently unknown but it has been suggested that $p g c$ might sequester critical components for PolII CTD phosphorylation for the transition from preinitiation complex to the elongation complex.

There are potentially other factors that are required in combination with $p g c$ to induce transcriptional repression in pole cells. These include germ cell-less ( $\mathrm{gcl}$ ), since a loss of function of this gene also causes premature transcriptional activation in pole cells although the underlying mechanism is unclear (Leatherman et al. 2002). nanos and pumilio also have a role in transcriptional repression in germ cell precursors (Hayashi et al. 2004). Thus, there are overlapping and redundant mechanisms involved in regulating transcriptional repression in the Drosophila pole cells.

Global transcriptional quiescence is also seen during the formation of germ cell precursors in C. elegans (Seydoux et al. 1996; Seydoux and Dunn 1997). However, the mechanism differs from that in Drosophila because of key differences in their early development. In C. elegans, the single $\mathrm{P}$ blastomere divides asymmetrically to give rise to a germ cell (P1) and a somatic daughter (AB). Following symmetric division of the P4 blastomere, Z2 and $\mathrm{Z} 3$ blastomeres become restricted to the germ line fate (Seydoux and Strome 1999). However, as in Drosophila, the P blastomeres destined for the germ line fate are initially repressed for the RNA PolII transcription, while the contemporary somatic daughters (from AB somatic cells) are transcriptionally active (Seydoux and Strome 1999). In the absence of transcriptional repression, germ line blastomeres adopt a somatic fate (Fig. 1). 
The early and rapid asymmetric division of a single blastomere generating a germ cell and a somatic cell in $C$. elegans requires a mechanism for transcriptional repression to be imposed in the P1 blastomere when the daughter cell acquires a somatic fate. However, initially, both the somatic and germ cell nuclei have an equivalent capacity for the initiation of transcription (Schaner et al. 2003). This is reflected in high levels of dimethylated lysine 4 of histone $\mathrm{H} 3$ (H3meK4), which is indicative of the potential for high transcriptional competence in germ cell blastomere (Schaner et al. 2003). However, transcription in the C. elegans germ cell precursors is repressed by PIE1 , a CCCH zinc finger protein that shows asymmetric segregation to the P blastomere (Mello et al. 1996; Seydoux et al. 1996; Seydoux and Strome 1999). PIE-1 competes with the recognition of the RNA polymerase II (PolII) CTD for the kinase complex, which is essential for the phosphorylation of PolII CTD and the release of the transcriptional complex (Zhang et al. 2003). PIE-1-mediated repression of transcription is unique to $C$. elegans, since there are no known homologs of the gene encoding PIE-1 in other organisms, suggesting that this mechanism for the specification of germ cells is restricted to C. elegans.

When the definitive germ cell precursors, Z2/Z3, are formed in C. elegans, PIE-1 is degraded but the transcriptional silencing still remains. This transcriptional silencing is evident in the loss of active chromatin markers such as H3K4 methylation. Interestingly, Drosophila pole cells also lack H3K4 methylation, but show high levels of H3K9 methylation. Altogether, germ cell precursors in both flies and worms carry hallmarks of transcriptional quiescence (Schaner et al. 2003). Loss of pgc in Drosophila, for example, results in the acquisition of H3K4 methylation and RNA PolII CTD serine 2 phosphorylation. These changes are associated with high transcriptional activity in pole cells similar to that in somatic cells (Deshpande et al. 2004; Martinho et al. 2004). Similar effects are seen in C. elegans following a loss of PIE1. However, one of the differences in the specification of germ cells in flies and worms is that the early and rapid asymmetric division of a single blastomere generating a germ cell and a somatic cell in C. elegans does not allow for a chromatin-based repression in the germ cell precursors and is instead in a permissive state for transcription (Schaner et al. 2003). However, as soon as the fate is restricted in $\mathrm{Z} 2 / \mathrm{Z3}$, then the same chromatin remodeling is observed as in the fly pole cells. Interestingly, nanos is required for transcriptional silencing in pole cells of Drosophila, and the lack of H3K4 methylation in Z2/Z3 cells in worms may also require nanos homologs, nos-1 and nos-2 (Schaner et al. 2003). Understanding how nanos could link germ cell chromatin remodeling is of high interest.

These studies on C. elegans and Drosophila illustrate that germ cell specification in response to the inheritance of germ plasm has some common features although the key proteins involved in the transcriptional repression are not conserved. Germ cell specification in mice, however, differs more markedly since there is no involvement of preformed germ cell determinants, and PGC specification occurs relatively late during development (Lawson and Hage 1994; McLaren 1999). Studies on PGC specification and the role of intrinsic epigenetic mechanisms that regulate transcription are just beginning to reveal their critical role in establishing the germ cell lineage. The mechanisms of global transcriptional repression that underlie germ cell specification in $C$. elegans and Drosophila are not feasible in mammals, where transcriptionally active pluripotent epiblast cells need to respond to extrinsic signals for the specification of both PGCs and somatic cells (Lawson et al. 1999). Nevertheless, as described below, germ cell specification in mammals also requires mechanisms for repression of somatic specific genes that are active in the neighboring cells. This may indeed be the key event of germ cell specification in mice and probably in all mammals.

\section{REPRESSION OF THE SOMATIC PROGRAM DURING PGC SPECIFICATION IN MICE}

Mouse development involves the onset of embryonic transcription at the two-cell stage followed by differentiation of the trophectoderm and inner cell mass, which contribute to the placenta and the embryo proper, respectively (Fig. 1). Specification of PGCs in mice is an instructive process in which the pluripotent epiblast cells serve as the precursors of both fetal somatic and germ cells. Evidence shows that the proximal epiblast cells of the embryonic day (E) 6.5 egg cylinder that give rise to germ cells have to be primed by signaling molecules, including bone morphogenetic protein 4 (BMP4), before they acquire competence to give rise to germ cells (Lawson and Hage 1994; Lawson et al. 1999). Thus, specification of germ cells in mice is an instructive process. At about E7.5, approximately 50 nascent PGCs can be detected (Lawson and Hage 1994; McLaren 1999). However, not all cells in the proximal epiblast give rise to germ cells as the majority go on to form the somatic extraembryonic mesodermal lineages (Lawson and Hage 1994). Therefore, PGC specification may involve not only the induction of a germ cell-specific program, but also a need to repress genes that instruct a somatic fate on neighboring cells. Our recent studies suggest that repression of the somatic program may involve epigenetic mechanisms as an essential component of PGC specification.

The acquisition of germ cell competence in E6.25 proximal epiblast cells results in the up-regulation of fragilis (Saitou et al. 2002; Tanaka and Matsui 2002), a gene that encodes a member of a family of transmembrane protein (Fig. 2). These genes are the homologs of the interferon inducible human Iftm gene family, of which members are predicted to be involved in homotypic cell adhesion and cell cycle elongation (Friedman et al. 1984; Evans et al. 1990, 1993; Deblandre et al. 1995). During gastrulation, fragilis expression shifts to the posterior region and intensifies in a region where the founder PGCs are eventually detected at E7.5. Expression of fragilis is not detected in the BMP4 homozygous mutants, and it is substantially reduced in heterozygous embryos, which suggests that fragilis expression is BMP4 dose-de- 


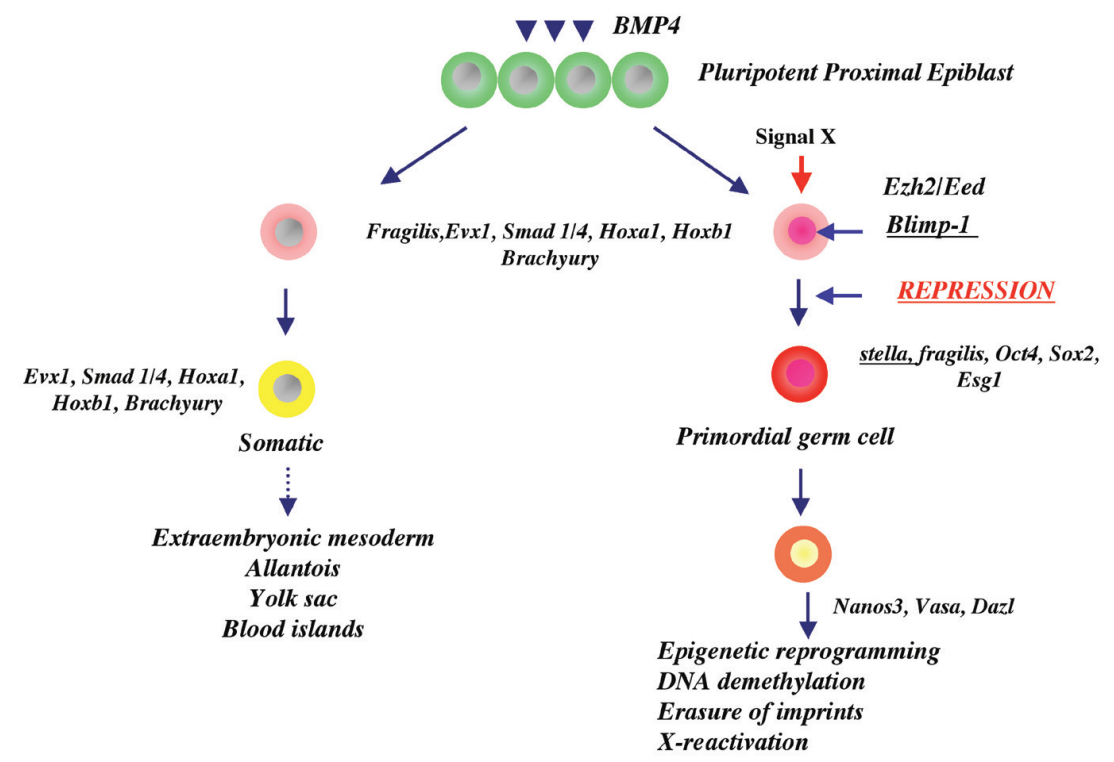

Figure 2. Specification and epigenetic regulation in the mouse germ cells. The pluripotent proximal epiblast cells of E6.25 embryos respond to BMP4 and other unknown signals (Signal X), which results in the initiation of Blimp-1 expression in a small group of epiblast cells. There is repression of genes, including Hox genes that are up-regulated in the neighboring somatic cells. This is apparently a critical event during PGC specification in mice. Subsequently, there is extensive epigenetic reprogramming of the genome in the germ cell lineage, including erasure of parental imprints and X-reactivation, followed by initiation of parental imprints later during gametogenesis.

pendent (Saitou et al. 2002). At the end of the specification, PGCs exhibit expression of stella, a nuclear protein with a SAP-like domain, within the center of the fragilis positive cell cluster. These stella-positive cells appear to be the lineage-restricted germ cells (Saitou et al. 2002).

Analysis of the stella-positive founder PGCs at E7.5 (early bud [EB] stage) and their somatic neighbors indicates that the germ cells initially share the gene expression program of cells destined to form the extraembryonic mesoderm cells. In particular, stella-positive PGCs show repression of the region-specific homeobox genes, including Hoxb1, Hoxal, and Evx1, which are all highly expressed in the neighboring somatic cells (Saitou et al. 2002). Since homeobox genes specify either the regional identity of cells along the body axis or induce differentiation of cells toward specific somatic cell lineages, our result suggests that the founder germ cells avoid somatic specification at least in part by preventing or suppressing homeobox gene expression (Fig. 2).

We have further evidence for active repression of the somatic program during PGC specification based on single-cell cDNA analysis at E7.25 (later streak [LS] stage) (Downs and Davies 1993). These cells are $\sim 6$ hours earlier than those described above, which express high amounts of fragilis, but not stella in significant amounts. Remarkably, they show high levels of Evxl expression, which is comparable to the levels in the neighboring somatic cells. Evxl is therefore clearly repressed in the founder PGCs, suggesting an active mechanism for the repression of this homeobox gene during PGC specification. Other genes, including Smad1 and Smad4 (U.C.
Lange, unpubl.), that are the transducers of BMP4 signaling are also apparently repressed, which suggests that germ cells shut off their response to BMP4 at the time of germ cell specification. These examples serve to illustrate that during PGC specification, there is probably extensive repression of genes essential for the specification of neighboring somatic mesodermal fate (Saitou et al. 2003). However, this proposed model requires further investigation.

To summarize the intrinsic events of PGC specification, we have proposed that the founder germ cells escape from a somatic cell fate through repression of the somatic program. At E7.0 (midstreak [MS] stage) shortly after gastrulation commences, cells located within the proximal-posterior region express genes such as T (Brachyury) that are associated with mesoderm formation. They are also strongly positive for the region-specific homeobox gene Evxl. At E7.25 (LS stage), there is a strong expression of fragilis in a subset of cells. Subsequently in cells that show expression of stella, there is a strong repression of HOX genes and of signal transducers Smadl and Smad4. These are the nascent PGCs detected at E7.5 (EB stage) with high expression of fragilis and stella, which eventually become lineage-restricted as germ cells. By contrast, in cells that do not up-regulate fragilis at the LS stage, expression of homeobox genes, such as Hoxbl and Hoxal, begins and expression of Evxl and the Smads is maintained. Although Oct4 as well as other genes, such as Ezh2 and Eed, are expressed at high levels in both somatic cells and germ cells at the time of germ cell specification, they are subsequently maintained exclusively or 
at higher levels, respectively, only in germ cells. The repression of the somatic program during the critical period of PGC specification is clearly a key event (Fig. 2). Elucidation of the mechanism underlying this process is likely to lead to a significant advance in the understanding of PGC specification in mice (Saitou et al. 2002, 2003).

\section{Blimp-1: A POTENTIAL REGULATOR OF PGC SPECIFICATION}

To begin to address the mechanism of repression of the somatic program during PGC specification, we examined expression of candidate genes that could be involved in this process. Among these are two members of the polycomb group $(\mathrm{PcG})$ proteins, Ezh2 and Eed, that are known to be associated with repression of Hox genes in Drosophila (Orlando 2003). These PcG group proteins are expressed during early development (O'Carroll et al. 2001; Erhardt et al. 2003) and to the same extent in both the founder PGCs and neighboring somatic cells. Despite this, it is possible that germ cell-specific factors may recruit these polycomb proteins to the Hox gene loci and repress their expression only in germ cells. Similarly, we also detected G9a expression in PGCs and somatic cells, which has the potential for methylation of histone H3 lysine 9 (H3meK9) within the euchromatin region (Tachibana et al. 2002). However, more significantly, we found that Blimp-1 was expressed exclusively in germ cells but not in the immediate neighboring somatic cells (Y. Ohinata et al., in prep.) (Fig. 2). Blimp-1, a transcriptional repressor, belongs to the RIZ family with a SET domain and five $\mathrm{C} 2 \mathrm{H} 2$ type zinc fingers toward the carboxyl terminus (Turner et al. 1994; Kouzarides 2002; Lachner and Jenuwein 2002). Although, there is no evidence at present that this protein with a SET domain has methyltransferase activity (Kouzarides 2002; Lachner and Jenuwein 2002), there is evidence that Blimp-1 can form repressive chromatin complexes with other proteins (Makar and Wilson 2004). It is also worth noting that Blimp-1 may also have a function in transcriptional activation through its acidic carboxyl terminus (Sciammas and Davis 2004). Blimp-1 is widely expressed in many tissues during development and therefore it probably has distinct functions in a context-dependent manner (Chang et al. 2002).

In the context of PGC specification, Blimp-1 expression is first detected among a group of fragilis-positive cells, which precedes the critical period of repression of Hox genes in the putative germ cells, and of the expression of stella that marks the end of PGC specification (Y. Ohinata et al., in prep.). When stella starts to be detectable, the number of Blimp-1-positive cells exceeds that of stella-positive cells at the late streak stage. Preliminary studies also suggest that Blimp-1 is critical for PGC specification, because their development is affected in Blimp-1 null embryos. A potential role of Blimp-1 may be to repress genes, including Hox genes, and this process may be affected in the absence of Blimp-1. As a result, the Blimp-1 mutant cells may acquire an alternative fate or undergo apoptosis. Studies are in progress to elucidate the precise role of Blimp-1 in PGC specification.

There is a precedent for the proposed role of Blimp-1 as a regulator in cell fate specification during terminal differentiation of B cells into Ig-secreting plasma cells. This event is associated with both the global repression of the B cell genetic program (Turner et al. 1994; Shaffer et al. 2002; Sciammas and Davis 2004), as well as of transcriptional activation of certain genes associated with the differentiation of plasma cells (Sciammas and Davis 2004). Indeed, it was originally described as a "master regulator" of plasma cell differentiation (Turner et al. 1994), because overexpression of Blimp-1 in BCL1 cells is sufficient to cause plasma cell differentiation. More remarkably, Blimp-1 apparently causes plasma cell differentiation through overall suppression of mature B cell-associated gene transcription, including $c M y c, I d 3$, Pax5, and others (Turner et al. 1994; Shaffer et al. 2002; Shapiro-Shelef et al. 2003; Sciammas and Davis 2004). The proposed repression of Pax5, detected in one study (Lin et al. 2002), may in turn lead to derepression of a number of other genes, leading to a major change in the transcriptome. Blimp-1-binding sites have been identified in these and other genes. These findings may serve as a paradigm for the specification of PGCs through suppression of somatic cell program.

A recent study suggests that a complex modular nature of Blimp-1 protein is capable of a variety of distinct functions, which is a hallmark of a significant and crucial regulator of transcription that could be critical for cell fate determination (Sciammas and Davis 2004). For example, there are several potential mechanisms by which Blimp1 could cause transcriptional repression of target genes, although there is as yet no evidence that the SET domain at the amino terminus of Blimp-1 has the enzymatic property for histone tail modifications. It has long been known that Blimp- 1 is involved in the postinduction repression of human interferon- $\beta$ (IFN $\beta$ ) gene transcription in response to viral induction. This could be accomplished through a proline-rich region located toward the amino terminus of Blimp-1 that can recruit repressor proteins Groucho and HDAC2 (Ren et al. 1999). However, more recent evidence shows that Blimp-1 can also recruit G9a, a histone $\mathrm{H} 3$ methyltransferase for lysine 9 (H3-2mK9), which is known to be active during early mouse development (Gyory et al. 2004). G9a is widely expressed in early postimplantation embryos and in germ cells, and loss of function of G9a is early embryonic lethal (Tachibana et al. 2002). This provides a potential for a repressive chromatin to form that could repress the somatic program during specification of PGCs in mice. What is also important is that the $\mathrm{C} 2 \mathrm{H} 2$ zinc fingers present in Blimp-1 have an essential role in inducing repression of IFN promoter (Keller and Maniatis 1992; Gyory et al. 2004). Thus, it is possible that Blimp-1 through its zinc fingers may target methyltransferase activity associated with G9a (and possibly other histone methylases in other contexts) to specific sites on a variety of genes. We also cannot entirely exclude a possibility that the SET domain of Blimp-1 itself may also have enzymatic activity capa- 
ble of histone modifications. These studies provide potential models that are compatible with Blimp-1-mediated repression of specific sets of genes during germ cell specification (Fig. 3).

From all the studies carried out so far, it is evident that transcriptional repression of somatic cell fate is a key component of germ cell specification in model organisms, although the mechanisms differ significantly among them. Different mechanisms are adopted in Drosophila and C. elegans, where global transcriptional repression is rapidly induced in the cells destined for the germ cell lineage. In mice, germ cell-competent cells are transcriptionally active at the time of germ cell specification. It also appears that the PGC-competent cells are initially destined for a somatic cell fate but this program is repressed during the critical period of PGC specification.

\section{PROPAGATION AND EPIGENETIC REPROGRAMMING OF THE GERM CELL LINEAGE}

Specification of the germ cell lineage involves distinct mechanisms that are not evolutionarily conserved in different organisms, where genes such as $\mathrm{pgc}$ and Piel have unique roles. Thus, distinct genetic pathways presumably generate specific chromatin states in founder germ cells. Some aspects of the propagation of the germ cell lineage may, however, rely, at least partially, on conserved homologous genes. Among these is Nanos, an RNA-binding protein and a translational repressor that is conserved among the germ cell lineage in different species (Schaner et al. 2003; Blackwell 2004). In Drosophila, nanos and pumilio are necessary for the maintenance of the germ cell lineage (Subramaniam and Seydoux 1999; Wang and Lin 2004). A recent study in Drosophila demonstrated that a lack of maternally inherited Nos leads to the loss of germ cell lineage by apoptosis, but when apoptosis was repressed, some of the Nos-negative germ cells adopted somatic fate and lost expression of the germ line-specific expression of Vasa (Hayashi et al. 2004). In C. elegans, nos- 1 and nos-2 have overlapping roles and their loss of function results in sterile adults, which is associated with aberrant H3meK4 modifications in germ cells (Subramaniam and Seydoux 1999; Schaner et al. 2003). In mice as

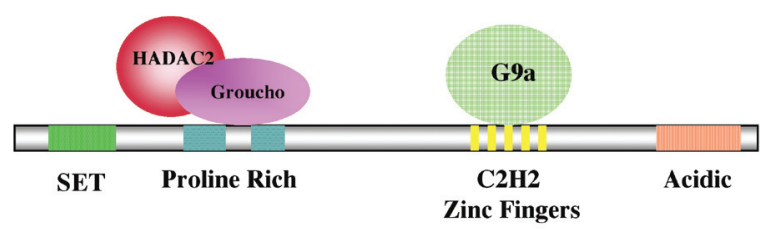

Figure 3. Blimp-1 protein and potential mechanisms of gene repression. Studies suggest that Blimp-1 could induce repression of target genes through a complex comprised of Groucho and HDAC2, or through recruitment of G9a histone methyltransferase. The five Kruppel-type zinc fingers may be essential for the recruitment of Blimp-1-dependent repressive chromatin to target sites. No function has yet been found for the SET domain that is present in Blimp-1. Blimp-1 can also induce transcription, perhaps through the acidic tail in the carboxyl terminus. well, nanos 2 has a role in maintaining spermatogenic stem cells, while loss of nanos 3 results in the loss of both male and female germ cells earlier during their migration into the gonads (Tsuda et al. 2003). Thus nanos 3 does not affect PGC specification but it clearly has a role in the maintenance of the lineage (Fig. 2).

Also of particular note is the potential role of Polycomb (PcG) genes, Ezh2 and eed, in the germ cell lineage. In mice, both these genes are expressed in embryonic cells at the time of germ cell specification, but their role is yet unclear. It is possible that this PcG complex plays an essential role through propagation of early cell fate decisions in germ cells and somatic cells. The role of Ezh2/Eed complex, which includes histone deacetylases in transcriptional repression, has been well documented (for review, see Cao and Zhang 2004). It has long been established that this complex can, for example, induce silencing of Hox genes. Ezh2 is a SET domain protein with the predominant activity for the methylation of histone H3 lysine 27 (H3meK27). The Ezh2/Eed complex is present throughout early preimplantation development in germ cells, oocytes, and in pluripotent stem cells in mice (O'Carroll et al. 2001; Erhardt et al. 2003). The role of these proteins in the mouse germ cell lineage is yet unclear.

In $C$. elegans, the role of PcG has been well established. Here MES-2 (counterpart of Ezh2), MES-3, and MES-6 (counterpart of Eed) function as a protein complex for transcriptional silencing (Seydoux and Strome 1999; Pirrotta 2002). As outlined above, PIE-1 is initially involved in transcriptional repression but this maternally inherited protein is eventually degraded at the 100-cell stage, while the expression of nos and mes genes continue. Recent studies reveal that the MES 2/3/6 complex is responsible for $\mathrm{H} 3 \mathrm{meK} 27$ methylation, as is the case with Ezh2/Eed complex in mice and humans (see Cao and Zhang 2004). Mutations in mes genes showed a marked alteration in $\mathrm{H} 3$ meK27 marks, which may explain the loss of transcriptional silencing in the germ cell lineage. This PcG complex is also detected in the mouse germ cell lineage from the time of specification and later when the germ cell lineage is established. The precise role of this complex in regulating the epigenetic status and maintenance of the germ cell lineage remains to be elucidated.

One significant property of the mouse germ cell lineage includes extensive epigenetic reprogramming, involving erasure and initiation of parental imprints (Surani 2001; Hajkova et al. 2002; Lee et al. 2002). In vivo, the erasure of imprints coincides with the entry of migrating PGCs into the developing gonads, which is a part of genome-wide DNA demethylation. Furthermore, in female embryos, the inactive $\mathrm{X}$ chromosome is also reactivated when germ cells reach the developing gonads. It is important to note that the erasure of imprints occurs in both male and female germ cells before the onset of sexual differentiation of developing gonads. By contrast, reinitiation of new parental imprints during gametogenesis is sex specific, as described elsewhere in this volume.

During maturation of the oocytes, there is also the maternal inheritance of epigenetic modifiers that are present in the mature oocyte, which have an essential role during early development (Erhardt et al. 2003). Among these are 
again the PcG proteins, Ezh2 and Eed. A detailed analysis of the role of these and other maternally inherited factors in the mammalian oocyte has yet to be carried out. Some of the factors present in the oocyte must also have a role in reprogramming of the somatic nucleus. It is of interest to consider if some of these factors and mechanisms are common to both the oocyte and PGCs at the time of the epigenetic reprogramming of the genome in the germ cell lineage.

\section{GERM CELLS AND STEM CELLS: REVERSIBLE PHENOTYPES}

Although PGCs are highly specialized cells with many unique properties, they retain an underlying pluripotency and show expression of pluripotency-associated genes such as Oct4. However, PGCs in vivo do not exhibit a tendency to undergo differentiation into diverse cell types, or to revert to an overtly pluripotent state. The maintenance of the phenotype could be attributed to the overlapping mechanisms that regulate transcriptional repression to ensure that PGCs do not undergo differentiation. PGCs are indeed highly refractory to differentiation even when transplanted to ectopic sites or into blastocysts. This is in contrast to the pluripotent epiblast or ES cells, which undergo differentiation into all the diverse cell types. This indicates that PGCs do not respond to the signals that induce differentiation of epiblast and ES cells.

There are, however, conditions in vitro that can erase epigenetic changes associated with the cell fate decision leading to PGC specification. When PGCs are cultured in vitro under specific conditions, which include exposure to FGF2, at least some of them revert to forming pluripotent stem cells called embryonic germ (EG) cells (Matsui et al. 1992; Donovan and de Miguel 2003). What intrinsic epigenetic mechanism leads to this phenotypic reversal is unknown. EG cells are very similar to ES cells that are derived from epiblast cells of blastocysts (DurcovaHills et al. 2001). However, EG cells exhibit erased imprints like their precursor PGCs in vivo (Tada et al. 1998). Pluripotent ES (and to a large extent EG) cells can, in turn, give rise to all somatic cells and germ cells in vivo when introduced into blastocysts, as well as when allowed to undergo differentiation in vitro. These studies demonstrate that PGCs and pluripotent stem cell states are potentially reversible.

\section{CONCLUSION}

The specification of germ cell lineage in many organisms involves repression of the somatic program. The mechanisms during this critical event appear not to be evolutionarily conserved. At one extreme are the organisms in which the germ line cell fate is dependent on maternally inherited germ plasm. These components act on establishing a global transcriptional silencing, by blocking RNA polII but also inducing a general refractory chromatin state. In Drosophila, transcriptional silencing is established in pole cells prior to the onset of zygotic transcription. In C. elegans, germ cell and somatic blastomeres are created from a single cell by the first asym- metric cell division. Since normal transcription is essential in the contemporary somatic daughter cell, the chromatin initially is in an active state for transcription. Here, preferential segregation of PIE-1, a zinc finger protein, in germ cell has a critical role in transcriptional repression through a mechanism affecting RNA processing. In mice, specification of PGCs is an instructive process and it involves yet another distinct mechanism. Following implantation, pluripotent epiblast cells commence differentiation into somatic and germ cells in response to signaling molecules. Cells that give rise to PGCs are transcriptionally active and initially indistinguishable from the neighboring cells, which give rise to the extraembryonic mesoderm. Repression of the somatic program in germ cells is thus a critical event during PGC specification. Blimp-1 may be a potential regulator of this process, perhaps through recruitment of other proteins, such as Groucho, HDAC2, and/or G9a, to generate a repressive chromatin.

The maintenance of the germ cell lineage probably requires overlapping redundant repression mechanisms. Indeed, PGCs in mice are highly refractory to phenotypic changes, suggesting that robust mechanisms ensure their propagation. This may be essential to ensure that germ cells that retain an underlying pluripotency do not differentiate into somatic cells or revert to an explicit pluripotent phenotype. Among the likely mechanisms are PcG group proteins, Ezh2 and Eed in particular, which are known to have a critical role in transcriptional regulation of early embryos, germ cells, and pluripotent stem cells.

A particularly noteworthy property of mouse PGCs is the extensive epigenetic reprogramming of the genome, including erasure and reestablishment of parental imprints, genome-wide DNA demethylation, and reactivation of the inactive $\mathrm{X}$ chromosome. The discovery of the underlying mechanism of this process will advance understanding of the regulation of genome functions through erasure and reestablishment of new epigenetic states.

\section{ACKNOWLEDGMENTS}

We thank the Wellcome Trust and BBSRC for grants in support of this work and all of our colleagues for their comments during the course of this work.

\section{REFERENCES}

Blackwell T.K. 2004. Germ cells: Finding programs of mass repression. Curr. Biol. 14: R229.

Cao R. and Zhang Y. 2004. The functions of E(Z)/EZH2-mediated methylation of lysine 27 in histone H3. Curr. Opin. Genet. Dev. 14: 155.

Chang D.H., Cattoretti G., and Calame K.L. 2002. The dynamic expression pattern of B lymphocyte induced maturation protein-1 (Blimp-1) during mouse embryonic development. Mech. Dev. 117: 305.

Deblandre G.A., Marinx O.P., Evans S.S., Majjaj S., Leo O., Caput D., Huez G.A., and Wathelet M.G. 1995. Expression cloning of an interferon-inducible 17-kDa membrane protein implicated in the control of cell growth. J. Biol. Chem. 270: 23860.

Deshpande G., Calhoun G., and Schedl P. 2004. Overlapping mechanisms function to establish transcriptional quiescence in the embryonic Drosophila germline. Development 131: 
1247

Donovan P.J. and de Miguel M.P. 2003. Turning germ cells into stem cells. Curr. Opin. Genet. Dev. 13: 463.

Downs K.M. and Davies T. 1993. Staging of gastrulating mouse embryos by morphological landmarks in the dissecting microscope. Development 118: 1255.

Durcova-Hills G., Ainscough J., and McLaren A. 2001. Pluripotential stem cells derived from migrating primordial germ cells. Differentiation 68: 220

Eddy E.M. 1975. Germ plasm and the differentiation of the germ cell line. Int. Rev. Cytol. 43: 229.

Erhardt S., Su I.H., Schneider R., Barton S., Bannister A.J., Perez-Burgos L., Jenuwein T., Kouzarides T., Tarakhovsky A., and Surani M.A. 2003. Consequences of the depletion of zygotic and embryonic enhancer of zeste 2 during preimplantation mouse development. Development 130: 4235.

Evans S.S., Collea R.P., Leasure J.A., and Lee D.B. 1993. IFNalpha induces homotypic adhesion and Leu-13 expression in human B lymphoid cells. J. Immunol. 150: 736.

Evans S.S., Lee D.B., Han T., Tomasi T.B., and Evans R.L. 1990. Monoclonal antibody to the interferon-inducible protein Leu-13 triggers aggregation and inhibits proliferation of leukemic B cells. Blood 76: 2583.

Extavour C.G. and Akam M. 2003. Mechanisms of germ cell specification across the metazoans: Epigenesis and preformation. Development 130: 5869

Friedman R.L., Manly S.P., McMahon M., Kerr I.M., and Stark G.R. 1984. Transcriptional and posttranscriptional regulation of interferon-induced gene expression in human cells. Cell 38: 745 .

Geijsen N., Horoschak M., Kim K., Gribnau J., Eggan K., and Daley G.Q. 2004. Derivation of embryonic germ cells and male gametes from embryonic stem cells. Nature 427: 148.

Gyory I., Wu J., Fejer G., Seto E., and Wright K.L. 2004. PRDI$\mathrm{BF} 1$ recruits the histone $\mathrm{H} 3$ methyltransferase G9a in transcriptional silencing. Nat. Immunol. 5: 299.

Hajkova P., Erhardt S., Lane N., Haaf T., El-Maarri O., Reik W., Walter J., and Surani M.A. 2002. Epigenetic reprogramming in mouse primordial germ cells. Mech. Dev. 117: 15.

Hayashi Y., Hayashi M., and Kobayashi S. 2004. Nanos suppresses somatic cell fate in Drosophila germ line. Proc. Natl. Acad. Sci. 101: 10338.

Hubner K., Fuhrmann G., Christenson L.K., Kehler J., Reinbold R., De La Fuente R., Wood J., Strauss J.F., III, Boiani M., and Scholer H.R. 2003. Derivation of oocytes from mouse embryonic stem cells. Science 300: 1251.

Keller A.D. and Maniatis T. 1992. Only two of the five zinc fingers of the eukaryotic transcriptional repressor PRDI-BF1 are required for sequence-specific DNA binding. Mol. Cell. Biol. 12: 1940

Kouzarides T. 2002. Histone methylation in transcriptional control. Curr. Opin. Genet. Dev. 12: 198.

Lachner M. and Jenuwein T. 2002. The many faces of histone lysine methylation. Curr. Opin. Cell Biol. 14: 286.

Lawson K.A. and Hage W.J. 1994. Clonal analysis of the origin of primordial germ cells in the mouse. Ciba Found. Symp. 182: 68 .

Lawson K.A., Dunn N.R., Roelen B.A., Zeinstra L.M., Davis A.M., Wright C.V., Korving J.P., and Hogan B.L. 1999. $\mathrm{Bmp} 4$ is required for the generation of primordial germ cells in the mouse embryo. Genes Dev. 13: 424.

Leatherman J.L. and Jongens T.A. 2003. Transcriptional silencing and translational control: Key features of early germline development. Bioessays 25: 326.

Leatherman J.L., Levin L., Boero J., and Jongens T.A. 2002. Germ cell-less acts to repress transcription during the establishment of the Drosophila germ cell lineage. Curr. Biol. 12: 1681.

Lee J., Inoue K., Ono R., Ogonuki N., Kohda T., Kaneko-Ishino T., Ogura A., and Ishino F. 2002. Erasing genomic imprinting memory in mouse clone embryos produced from day 11.5 primordial germ cells. Development 129: 1807.

Lin K.I., Angelin-Duclos C., Kuo T.C., and Calame K. 2002. Blimp-1-dependent repression of Pax-5 is required for differ- entiation of B cells to immunoglobulin M-secreting plasma cells. Mol. Cell. Biol. 22: 4771.

Makar K.W. and Wilson C.B. 2004. Sounds of a silent Blimp-1. Nat. Immunol. 5: 241.

Martinho R.G., Kunwar P.S., Casanova J., and Lehmann R. 2004. A noncoding RNA is required for the repression of RNApolII-dependent transcription in primordial germ cells. Curr. Biol. 14: 159.

Matsui Y., Zsebo K., and Hogan B.L. 1992. Derivation of pluripotential embryonic stem cells from murine primordial germ cells in culture. Cell 70: 841 .

McLaren A. 1999. Signaling for germ cells. Genes Dev. 13: 373.

Mello C.C., Schubert C., Draper B., Zhang W., Lobel R., and Priess J.R. 1996. The PIE-1 protein and germline specification in C. elegans embryos. Nature 382: 710.

O'Carroll D., Erhardt S., Pagani M., Barton S.C., Surani M.A., and Jenuwein T. 2001. The polycomb-group gene Ezh2 is required for early mouse development. Mol. Cell. Biol. 21: 4330.

Orlando V. 2003. Polycomb, epigenomes, and control of cell identity. Cell 112: 599.

Pirrotta V. 2002. Silence in the germ. Cell 110: 661 .

Ren B., Chee K.J., Kim T.H., and Maniatis T. 1999. PRDIBF1/Blimp-1 repression is mediated by corepressors of the Groucho family of proteins. Genes Dev. 13: 125.

Saitou M., Barton S.C., and Surani M.A. 2002. A molecular program for the specification of germ cell fate in mice. Nature 418: 293 .

Saitou M., Payer B., Lange U.C., Erhardt S., Barton S.C., and Surani M.A. 2003. Specification of germ cell fate in mice. Philos. Trans. R. Soc. Lond. B Biol. Sci. 358: 1363.

Schaner C.E., Deshpande G., Schedl P.D., and Kelly W.G. 2003. A conserved chromatin architecture marks and maintains the restricted germ cell lineage in worms and flies. Dev. Cell 5: 747.

Sciammas R. and Davis M.M. 2004. Modular nature of Blimp-1 in the regulation of gene expression during $\mathrm{B}$ cell maturation. J. Immunol. 172: 5427.

Seydoux G. and Dunn M.A. 1997. Transcriptionally repressed germ cells lack a subpopulation of phosphorylated RNA polymerase II in early embryos of Caenorhabditis elegans and Drosophila melanogaster. Development 124: 2191

Seydoux G. and Strome S. 1999. Launching the germline in Caenorhabditis elegans: Regulation of gene expression in early germ cells. Development 126: 3275 .

Seydoux G., Mello C.C., Pettitt J., Wood W.B., Priess J.R., and Fire A. 1996. Repression of gene expression in the embryonic germ lineage of C. elegans. Nature 382: 713.

Shaffer A.L., Lin K.I., Kuo T.C., Yu X., Hurt E.M., Rosenwald A., Giltnane J.M., Yang L., Zhao H., Calame K., and Staudt L.M. 2002. Blimp-1 orchestrates plasma cell differentiation by extinguishing the mature $\mathrm{B}$ cell gene expression program. Immunity 17: 51 .

Shapiro-Shelef M., Lin K.I., McHeyzer-Williams L.J., Liao J., McHeyzer-Williams M.G., and Calame K. 2003. Blimp-1 is required for the formation of immunoglobulin secreting plasma cells and pre-plasma memory B cells. Immunity 19: 607.

Subramaniam K. and Seydoux G. 1999. nos-1 and nos-2, two genes related to Drosophila nanos, regulate primordial germ cell development and survival in Caenorhabditis elegans. Development 126: 4861.

Surani M.A. 2001. Reprogramming of genome function through epigenetic inheritance. Nature 414: 122. 427: 106

Tachibana M., Sugimoto K., Nozaki M., Ueda J., Ohta T., Ohki M., Fukuda M., Takeda N., Niida H., Kato H., and Shinkai Y. 2002. G9a histone methyltransferase plays a dominant role in euchromatic histone $\mathrm{H} 3$ lysine 9 methylation and is essential for early embryogenesis. Genes Dev. 16: 1779.

Tada T., Tada M., Hilton K., Barton S.C., Sado T., Takagi N., and Surani M.A. 1998. Epigenotype switching of imprintable loci in embryonic germ cells. Dev. Genes Evol. 207: 551. 
Tanaka S.S. and Matsui Y. 2002. Developmentally regulated expression of mil-1 and mil-2, mouse interferon-induced transmembrane protein like genes, during formation and differentiation of primordial germ cells. Mech. Dev. (suppl. 1) 119: S261.

Toyooka Y., Tsunekawa N., Akasu R., and Noce T. 2003. Embryonic stem cells can form germ cells in vitro. Proc. Natl. Acad. Sci. 100: 11457.

Tsuda M., Sasaoka Y., Kiso M., Abe K., Haraguchi S. Kobayashi S., and Saga Y. 2003. Conserved role of nanos proteins in germ cell development. Science 301: 1239.

Turner C.A., Jr., Mack D.H., and Davis M.M. 1994. Blimp-1, a novel zinc finger-containing protein that can drive the maturation of B lymphocytes into immunoglobulin-secreting cells. Cell 77: 297.

Van Doren M., Williamson A.L., and Lehmann R. 1998. Regulation of zygotic gene expression in Drosophila primordial germ cells. Curr. Biol. 8: 243.

Wang Z. and Lin H. 2004. Nanos maintains germline stem cell self-renewal by preventing differentiation. Science 303: 2016. Wylie C. 1999. Germ cells. Cell 96: 165.

Zhang F., Barboric M., Blackwell T.K., and Peterlin B.M. 2003. A model of repression: CTD analogs and PIE-1 inhibit transcriptional elongation by P-TEFb. Genes Dev. 17: 748. 


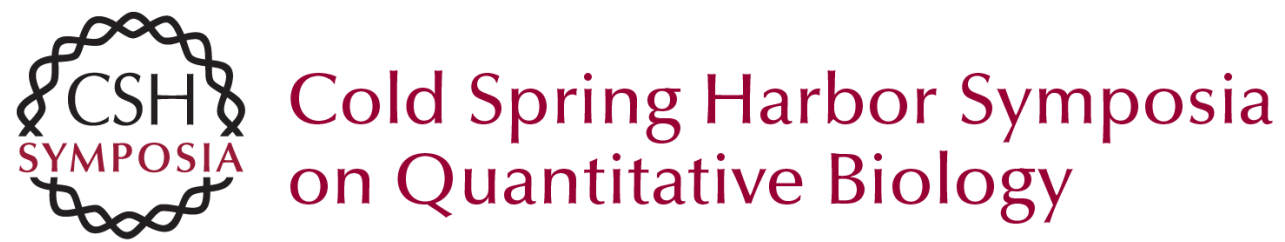

\section{Mechanism of Mouse Germ Cell Specification: A Genetic Program Regulating Epigenetic Reprogramming}

M.A. SURANI, K. ANCELIN, P. HAJKOVA, et al.

Cold Spring Harb Symp Quant Biol 2004 69: 1-10

Access the most recent version at doi:10.1101/sqb.2004.69.1

References This article cites 59 articles, 24 of which can be accessed free at:

http://symposium.cshlp.org/content/69/1.full.html\#ref-list-1

\section{License}

Email Alerting

Receive free email alerts when new articles cite this article - sign up in Service the box at the top right corner of the article or click here. 